problem of memory the final convergence of psychology and neurophysiology offers. One has the nagging feeling that many experimenters are not sufficiently sensitive to psychometric issues-reliability, scaling procedures, transformations, and so on, which might alter the implications of their experimental data and statistical treatment. Canestrari (chapter 6) considers age changes in acquisition (learning) with particular reference to stimulus intervals and mediators. His chapter is relatively short and simple and he raises the problem of remedial treatment for age deficits-a much neglected issue. Eisdorfer writes about arousal and performance using experiments in verbal learning and offering a tentative theory. He includes a section on the relationship between verbal rote learning and free fatty acid level. In the eighth chapter Davies deals with age differences in paced inspection tasks. The contents of this chapter and several others overlap somewhat but without seeming repetitive. As in some other chapters, the numbers of Ss used in the experiments are uncomfortably small. Riegel in chapter 9 deals with age changes in psycholinguistic performances - a research area which promises to be extremely interesting, although one could argue that it might be better to await developments in psycholinguisties generally beforo embarking on expensive, difficult and time-consuming research into the effects of ageing, since we are not yet certain what are the crucial aspects of verbal performance. Riegel's results indicate that although age differences are not large, the study of verbal processes promises to be perhaps the bost way of studying complex cognitive functions. The chapter is so condensed as to be obscure in parts but still makes interesting reading. Schaie and Strother consider cognitive and personality variables in college graduates of advanced age. This chapter is quite different from the rest, being largely descriptive and less rigorously experimental.

Readers will need some knowledge of modern experimental psychology and will profit more if they know something about the general psychology of ageing, so that they can pick up the occasional references to possible (or excluded) explanations-motivation, confidence, sampling, and so on, for the experimental findings. Otherwise little mention is made of the general problems of sampling and methodology in research in ageing. D. B. BromLey

\section{FOXES IN THE WILD}

\section{Wild Fox}

By Roger Burrows. (David and Charles (Publishers): Newton Abbott, Devon, 1968.) 42s.

THE fly-leaf states that this " . . book is generally intended for the naturalist and interested layman", but "it is hoped that it will have a particular appeal to the young natural historian as a guide to how a field study problem can be successfully tackled by simple moans". "To this end the book fulfils its function. Inevitably there are pitfalls in the interpretation of the behaviour of foxes in the wild which this book is mostly about. Happily the author has been at pains to avoid these, and it is particularly gratifying to find little anthropomorphism in the text.

Field observations were made over a three-year period on a number of wild foxes ncar Gloucester. The author's findings do not rank with the excellent work on the badger (Neal, E. G., The Badger, Collins, 1948), but there is an interesting compilation of field observations about the evidence for the presence of foxes, a monthly calendar of fox-watching, a chapter on senses (hearing, smell and sight), statistics-concerning colour, weight, body measurements, but no population dynamics. The chapter on ecology deals briefly with population density. "Music and Movement", diet and other aspects of fox behaviour are included in this book. There are a number of statements which one would like to see supported by more evidence, and some which need clarification, for example, page 56, " . . voles form an almost staple part of their diet"; two graphs (not histograms) in which small rodents, rabbits and birds are plotted against the seasons for two years show a quantitive analysis of food; this is done on a volume percentage basis, and there is a series of histograms on page 106 three of which show (by percentago occurrence) a considerably greater proportion of "rabbits and hares" than "total rodents". Again on page 107, ". . . even at times of peak predation on voles, the bulk of the food is derived from other sources, mainly fruit and birds when rabbits are not available". On page 110 it is stated that the only animal capable of carrying off a dead fox is another fox: the reviewer has seen a badger removing a dead dog (bigger than a fox) from a road! No mention is made of the "submission reaction" when an animal rolls on its back in the presence of an individual of a higher "peck order".

The author's studies are strictly local, but he has incorporated informacion from other books, including those of foreign investigators. Some of the tables in the appendices do not give the number of individual samples from which the averages are derived, though fortunately it is stated that these are based mainly on information by other authors whose works are quoted in the useful bibliography. Table $D$ is given in millimetres (not centimetres as stated) and the last two columns appear to be printed one line too low, which makes the figures for Russian foxes very strange reading.

There are not too many printing errors: on page 164 Lorentz should read Lorenz; page 157, Calium should read Galium and the specific name of the woodmouse on plate $10 a$ should have an initial small letter. The photographs are interesting and mostly of a high quality, though plates $4 a$ and $4 b$ leave something to be desired.

This book does not add a great deal to the scientific knowledge of the fox, but it performs the useful function of indicating where further field observations are needed on ". . . this little known yet extremely common animal". JoHN SANkeY

\section{University News}

Mr G. A. Hoare has been appointed to the chair of computer science and Dr W. D. Ryan to the chair of electronies in the Queen's University of Belfast.

Dr E. Smith, Central Electricity Research Laboratories, Leatherhead, has been appointed professor of metallurgy in the University of Manchester on the resignation of Professor C. R. Tottle.

Dr F. J. G. Ebling has been appointed to the second chair of zoology in the University of Sheffield.

Dr E. D. Acheson, University of Oxford, has been appointed dean of medicine and professor of clinical epidemiology in the University of Southampton from October 1, 1968. This is the first appointment to the staff of the new medical school which is to open in October 1971.

\section{Announcements}

Professor F. Graham Smith, University of Manchester, has been appointed part-time deputy director of the Radio and Space Research Station for a period of two years from January 1,1969 , on the retirement of $\mathrm{Mr}$ A. F. Wilkins.

Dr C. E. Stroud has been appointed to the chair of child health tenable at King's College Hospital Medical School, and the title of professor of organic chemistry has been conferred on Dr T. G. Bonner in respect of his post at Royal Holloway College, London. 